\title{
As políticas brasileiras e internacionais de incentivo ao trabalho de pessoas com deficiência: uma reflexáo ${ }^{1}$
}

\author{
Angela Paula Simonelli, João Alberto Camarotto
}

\begin{abstract}
Resumo: A Convenção 159 sobre Reabilitação Profissional e Emprego de Pessoas com Deficiência, da Organização Internacional do Trabalho, aprovada em 1983, considera deficiente para o trabalho todas as pessoas cujas possibilidades de obter e conservar um emprego adequado, e de progredir no mesmo, fiquem substancialmente reduzidas em função de uma deficiência de caráter físico ou mental devidamente comprovada. Essa norma internacional, incorporada pelo Brasil por meio do Decreto ${ }^{\circ} 129$ de 1991, ressalta que medidas com a finalidade de atingir igualdade efetiva de oportunidades e de tratamento entre trabalhadores com deficiência e os demais trabalhadores devam ser adotadas por países signatários. Cada sociedade faz opção pela maneira com a qual fará a inclusão no trabalho das pessoas com deficiência. Algumas utilizam o sistema de cotas isoladas, leis antidiscriminatórias, outras agregam ambas as iniciativas, porém em todas as sociedades há a previsão de mecanismos facilitadores para as pessoas que requerem condições especiais para trabalhar. Este artigo, por meio de uma revisão bibliográfica, tem por objetivo apresentar as políticas internacionais para a inclusão de pessoas com deficiência no trabalho e a Lei $\mathrm{n}^{\circ}$ 8213/91, em vigor no Brasil, discutindo a necessidade da garantia dos direitos trabalhistas e os riscos de precarização do trabalho.
\end{abstract}

Palavras-chave: Saúde do Trabalhador, Pessoas com Deficiência, Políticas Públicas.

\section{The Brazilian and international policies to incentive to work for people with disabilities: a reflection}

\begin{abstract}
The convention 159 about Professional Rehabilitation and Employment of People with Disabilities from the International Work Organization, approved in 1983, considers inadequate for work all people whose chances to obtain and maintain suitable employment with improvement are substantially reduced due to physical or mental impairment properlydiagnosed. This international standard, incorporated inthe Brazilian legislation through the Law Decree \#129/91, emphasizes that measures with the purpose of achieving effective equality of opportunities and treatment between impaired workers and other workers should be adopted by signatory countries. Each society makes an option on how to include impaired people in the market. Some use the quota system, others anti-discrimination laws, and others aggregate both initiatives; but in all societies there is a provision of facilitating mechanisms for people who require special conditions at work. This article, through a theoretical review, aims to present the international policies for the inclusion of people with impairment at work and the Quota Law in Brazil (Law \#8213/91), discussing the need to ensure working rights and avoid risks of precarious employment.
\end{abstract}

Keywords: Occupational Health, Disabled People, Public Policies, Review.

\section{Introdução}

A Organização Mundial de Saúde (OMS) apontou que, no ano de 1992, cerca de 10\% dos habitantes de todo o mundo apresentavam algum tipo de deficiência ${ }^{2}$ (ORGANIZAÇÃO..., 1992). O Censo 2000 do Instituto Brasileiro de Geografia e Estatística (IBGE), cujos dados finalizados foram 
divulgados no início de 2003, mostrou que as pessoas com deficiência estão em número maior na nossa sociedade, cerca de 24,6 milhóes de pessoas ou $14,5 \%$ da população brasileira apresentava algum tipo de deficiência (INSTITUTO..., 2001).

De acordo com os dados do Instituto... (2001), a predominância foi de pessoas com deficiência visual (48,1\%), seguida de deficiência motora $(22,9 \%)$, deficiência auditiva $(16,7 \%)$, deficiência mental $(8,3 \%)$ e deficiência física (4,1\%). Em números absolutos, esses dados indicaram que existiam 16,5 milhóes de pessoas com deficiência visual no País. Desse total, 159.824 eram incapazes de enxergar. Além disso, 5,7 milhóes de brasileiros apresentavam deficiência auditiva, dos quais 176.067 eram incapazes de ouvir. Existiam ainda 2,8 milhóes de pessoas com deficiência mental, 7,9 milhóes de pessoas incapazes ou com grande dificuldade de caminhar, subir escadas, 937 mil pessoas com paraplegia, tetraplegia ou hemiplegia, e 478 mil com falta de um membro ou parte dele (INSTITUTO..., 2001).

O conceito ampliado utilizado no Censo 2000, que incluiu diversos graus de incapacidade para enxergar, ouvir e locomover-se, é compatível com a Classificação Internacional de Funcionalidade, Incapacidade e Saúde (CIF) divulgada, em 2001, pela OMS. A utilização dos conceitos da CIF resultou no aumento do número de pessoas com deficiência visual declarada; no entanto, deve-se considerar que apenas 159.824 eram incapazes de enxergar e o restante compreende perdas de acuidade visual em graus variados, náo impossibilitando a funçáo com uso de órteses ou tecnologias apropriadas (BUCHALLA, 2003).

Segundo os dados do Instituto... (2001), a deficiência mental, física (especialmente na falta de um membro ou parte dele) e auditiva era predominante no gênero masculino. Diversamente, entre o gênero feminino, havia predominância de dificuldades motoras (incapacidades de caminhar ou subir escadas) e visuais. Na comparaçáo por Estados, a maior proporção de pessoas com deficiência se encontrava no Nordeste $(16,8 \%)$ e a menor, no Sudeste (13,1\%).

Informaçôes da projeção da população divulgadas em 2004 pelo IBGE apresentaram que no Brasil existiam 16,4 milhóes de pessoas com deficiência em idade de trabalhar (CLEMENTE, 2005) e, segundo dados da Relação Anual de Informaçôes Sociais (RAIS) e do Ministério do Trabalho e Emprego (MTE), essas pessoas representavam $2 \%$ do total de trabalhadores formais do Brasil, o que revelou baixa empregabilidade. Estavam proporcionalmente mais presentes na indústria do que os trabalhadores em geral (27,3 e 19,3\%, respectivamente), tinham participação proporcional semelhante no setor de serviços, mas estavam bem abaixo na proporçáo de empregados na agricultura e na construção civil (BRASIL, 2002).

Para reverter o quadro de baixa empregabilidade de pessoas com deficiência, o Brasil investiu em uma política afirmativa a fim de garantir a participação na produção e no consumo de bens e valores sociais. Desde a regulamentaçáo de sua vigência pelo Decreto 3298/99, a Lei de Cotas (Lei 8213/91) fixa percentual de vagas em empresas do setor privado que devem ser preenchidas por pessoas com deficiência. As empresas com 100 a 200 funcionários são obrigadas a reservar $2 \%$ de seus postos de trabalho e as empresas que empregam de 201 a 500 funcionários devem reservar 3\%. Nas empresas com 501 a 1.000 funcionários, a cota exigida é de $4 \%$ e aquelas com mais de 1.000 funcionários devem contratar pessoas com deficiência para $5 \%$ de suas vagas de trabalho (BRASIL, 1991; 1999).

Segundo dados da Secretaria de Inspeção do Trabalho do MTE, foram incluídas no mercado de trabalho 143.631 pessoas com deficiência desde 2005, revelando um aumento no número de inserções ano a ano: em 2005, foram 12.786 e, ao final de 2010, 28.752. Esses dados representam um aumento de 124,8\% em cinco anos (BRASIL, 2011).

Nos três primeiros meses de 2011, 7.508 pessoas com algum tipo de deficiência foram inseridas no mercado de trabalho formal, representando um crescimento de $40,7 \%$ em relação ao primeiro trimestre de 2010, quando foram incluídos 5.338 trabalhadores (BRASIL, 2011).

Verifica-se, por meio dos dados supracitados, a representatividade das pessoas com deficiência na sociedade brasileira, o que direciona para uma reflexão sobre a importância da inserção social dessas pessoas no mercado de trabalho. Para tanto, objetiva-se, por meio de revisão bibliográfica, apresentar as políticas internacionais para a inclusão de pessoas com deficiência no trabalho e a Lei 8213/91, em vigor no Brasil, além de discutir a necessidade da garantia dos direitos trabalhistas e os riscos de precarização do trabalho.

\section{Políticas internacionais de incentivo ao trabalho para pessoas com deficiência}

A partir da Convenção no 159/83, da Organização Internacional do Trabalho (OIT), cujo princípio 
fundamenta-se na garantia de emprego adequado e na possibilidade de integração ou reintegração das pessoas com deficiência na sociedade, todo Estado que ratificar a Convenção deve formular e aplicar uma política nacional sobre readaptação profissional e emprego de pessoas com deficiência, e garantir que as medidas, efetivamente, beneficiem todos os que se encontram nessa condição (ORGANIZAÇÃO..., 1983).

As políticas internacionais de incentivo ao trabalho das pessoas com deficiência vão desde a reserva obrigatória de vagas até incentivos fiscais e contribuiçóes empresariais em favor de fundos públicos destinados ao custeio de programas de formação profissional, nos âmbitos público e privado (VASCONCELOS, 2006). O Quadro 1 sintetiza as políticas adotadas no panorama internacional.

Os sistemas de reserva de mercado para pessoas com deficiência foram desenvolvidos em países europeus no início do século XX, com o objetivo de empregar os feridos da Primeira Guerra Mundial. Esse modelo foi primeiramente estabelecido nos seguintes países: Alemanha, Áustria, França, Itália e Polônia (PASTORE, 2000). Em países, como Dinamarca, Suécia (KARLSSON, 1998), Finlândia (DUCKWORTH et al., 1998), Estados Unidos (O'LEARY; DEAN, 1998) e Canadá (GUNDERSON; GILDINER; KING, 1998), as ações voltadas à empregabilidade das pessoas com deficiência não foram realizadas por meio de sistemas de cotas. Na Dinamarca, existe um sistema de acesso preferencial dessas pessoas a algumas profissóes e atividades. Na Suécia, várias leis garantem recursos financeiros e técnicos para os empregadores fazerem acomodaçóes, proteção, retenção e promoção das pessoas com deficiência. Nos Estados Unidos, os programas também se baseiam em uma lei antidiscriminação - Americans with Disabilities Act - ADA. Na União Soviética, após a Primeira Guerra Mundial, a contratação de pessoas com deficiência era realizada por meio de reserva de vagas pelo Estado (VASCONCELOS, 2006).

Nos países citados, argumenta-se ser impossível legislar com o propósito de garantir cotas para pessoas com deficiência, sem garantir o mesmo direito para outros grupos minoritários (PASTORE, 2000).

A OIT, em 1923, recomendou o desenvolvimento de leis nacionais que obrigassem as entidades públicas e privadas a contratarem um número de pessoas com deficiência originada por guerra. Em 1944, a OIT, na Reunião de Filadélfia, aprovou a recomendaçáo para que países membros contratassem pessoas com deficiência não combatentes. Os primeiros países que adotaram as recomendaçóes foram a Inglaterra e a Holanda, sendo seguidas por Grécia, Espanha, Irlanda e Bélgica. O Japão adotou a recomendação em 1960, acoplando-a, em 1976, ao sistema de contribuição, no qual o empregador deveria contribuir para um fundo público destinado à habilitação e à reabilitação profissional das pessoas com deficiência. Em 1998, o Japão modificou seu sistema, passando a estimular as empresas à contratação de pessoas com deficiência. Na década de 1980, Malásia, Filipinas, Angola, Tanzânia, Egito e Turquia também adotaram o sistema de cotas, que faz uma reserva de vagas no mercado para a contrataçáo de pessoas com deficiência. Na década de 1990, países da ex-Europa Oriental - Ucrânia, Lituânia e Bielo-Rússia - e China adotaram cotas. Em 2000, dois terços dos países da Europa possuíam cotas legais e compulsórias, sendo a maioria baseada em sistemas de cota-contribuição, nos quais a empresa tinha a obrigação legal de contratar pessoas com deficiência, mas poderia contribuir para um fundo público destinado à habilitação e à reabilitação profissional dessas pessoas quando comprovassem impossibilidade imediata de contratação (THORNTON, 1999). O percentual das cotas varia entre 1,5 e $7 \%$, mas, em muitos casos, é fixado em função do tamanho da empresa.

\section{Políticas brasileiras para a inclusão de pessoas com deficiência no trabalho}

Em 1986, sob influência de mobilização nacional e internacional de entidades de defesa das pessoas com deficiência, o governo brasileiro editou o Decreto $\mathrm{n}^{\circ}$ 93.481, que criou, no Gabinete Civil da Presidência

Quadro 1. Panorama internacional das políticas de inclusão de pessoas com deficiência no mercado de trabalho em linha cronológica com grandes acontecimentos mundiais.

\begin{tabular}{|c|c|c|c|c|c|}
\hline 1986 & 1988 & 1991 & 1999 & 2004 & 2004 \\
\hline \begin{tabular}{|c|} 
Decreto 93.481 \\
Criação da \\
CORDE.
\end{tabular} & $\begin{array}{c}\text { Constituição } \\
\text { Brasileira } \\
\text { Incorporação } \\
\text { da Convenção } \\
159 / 83 \text { da OIT. }\end{array}$ & $\begin{array}{l}\text { Lei } 8213 / 91 \\
\text { Lei de Cotas. }\end{array}$ & $\begin{array}{c}\text { Decreto } \\
3298 .\end{array}$ & $\begin{array}{c}\text { Resolução n. } 17 \text { Alteração } \\
\text { no dimensionamento das } \\
\text { condições médicas do } \\
\text { decreto 3298/99 para D.A } \\
\text { e D.V. }\end{array}$ & $\begin{array}{c}\text { Decreto } 5296 \text { inclui } \\
\text { os reabilitados do } \\
\text { INSS nas cotas } \\
\text { previstas pela lei } \\
8213 / 91 .\end{array}$ \\
\hline
\end{tabular}


da República, a Coordenadoria para Integração da Pessoa Portadora de Deficiência ${ }^{3}$ - CORDE, visando dar tratamento prioritário e adequado aos assuntos relativos às pessoas com deficiências, para assegurar-lhes o pleno exercício de seus direitos básicos e a efetiva integração social (BRASIL, 1986).

A Constituição de 1988 amplia as normas vigentes, destacando-se a proibiçáo de qualquer discriminação no tocante a salário e critérios de admissão do trabalhador com deficiência (art. 7o, XXXI); a definição de que a lei reserva percentual de cargos e empregos públicos para as pessoas com deficiência e os critérios de sua admissão (art. 37, VIII), e a garantia de habilitação e reabilitação das pessoas com deficiência e a promoção de sua integração à vida comunitária (art. 203, IV), dentre outros direitos (BRASIL, 1988).

Foi apenas depois da Segunda Guerra Mundial que a afirmação da cidadania se completou. Percebeu-se a necessidade de valorizar a vontade da maioria, respeitando-se, sobretudo, as minorias, suas necessidades e peculiaridades. Quanto à pessoa com deficiência, buscou-se no Brasil, com a criação da Lei de Cotas, superar o assistencialismo excludente para possibilitar-lhes a inclusão efetiva (BRASIL, 2007).

No Brasil, há duas normas internacionais ratificadas, sendo, portanto, leis nacionais, que são a Convenção no 159/83 da OIT e a Convençáo Interamericana para a Eliminação de Todas as Formas de Discriminação Contra as Pessoas Portadoras de Deficiência, esta também conhecida como Convenção da Guatemala, de 1999. Ambas conceituam deficiência, para fins legais, como uma limitação física, mental, sensorial ou múltipla, que incapacite a pessoa para o exercício de atividades normais da vida e que, em razão dessa incapacitação, a pessoa tenha dificuldades de inserção social
(ORGANIZAÇÃO..., 1983). O Decreto no 3298/99, que definiu as condiçóes médicas que permitem enquadrar uma pessoa como deficiente e cuja redação foi atualizada após longas discussóes no Conselho Nacional dos Direitos da Pessoa Portadora de Deficiência (CONADE), pelo Decreto no 5926/04, inclui nas cotas as pessoas reabilitadas que, por sua vez, são aquelas que se submeteram a programas oficiais de recuperação da atividade laboral, perdida em decorrência de infortúnio. Tal condição deve ser atestada por documentos públicos oficiais, expedidos pelo Instituto Nacional de Seguro Social (INSS) ou por órgãos que exerçam função por este delegada (BRASIL, 2007).

O Quadro 2 apresenta as políticas públicas ratificadas no Brasil para a inclusão das pessoas com deficiência no mercado de trabalho.

A Lei no 8213/91, ao fixar para as empresas uma percentagem de contratação obrigatória de pessoas com deficiência habilitadas ou reabilitadas, está a exercer uma iniciativa de combinação de esforços entre o Estado e a sociedade civil, decorrente de lei.

A contratação de pessoas com deficiência deve ser vista como qualquer outra, na medida em que se esperam do trabalhador nessas condiçóes profissionalismo, dedicaçáo e assiduidade; enfim, atributos ínsitos a qualquer empregado (BRASIL, 2007). Trata-se de materializar a igualdade real entre as pessoas a partir do pensamento de que a verdadeira igualdade consiste em se tratar igualmente os iguais e desigualmente os desiguais, na justa medida da desigualdade.

No Brasil, as empresas devem cumprir a lei, esforçando-se em programas de formação profissional e flexibilizando as exigências genéricas para a composição de seus quadros, de modo a, objetivamente, abrir suas portas a esse grupo social.

Quadro 2. Linha cronológica das políticas públicas brasileiras para a inclusão das pessoas com deficiência no mercado de trabalho.

\begin{tabular}{|c|c|c|c|c|c|c|}
\hline & \multicolumn{3}{|c|}{$\begin{array}{c}\text { Após a } \\
\text { Primeira Guerra Mundial }\end{array}$} & $\begin{array}{c}\text { Após Segunda Guerra } \\
\text { Mundial }\end{array}$ & \multicolumn{2}{c|}{$\begin{array}{c}\text { De 1976 à } \\
1999\end{array}$} \\
\hline $\begin{array}{c}\text { Modelo } \\
\text { Adotado }\end{array}$ & $\begin{array}{c}\text { Sistema de } \\
\text { cotas para } \\
\text { feridos de } \\
\text { guerra. }\end{array}$ & $\begin{array}{c}\text { Políticas de } \\
\text { leis } \\
\text { antidiscriminatórias. }\end{array}$ & $\begin{array}{c}\text { Emprego } \\
\text { reservado } \\
\text { pelo } \\
\text { estado. }\end{array}$ & $\begin{array}{c}\text { Sistema de cotas } \\
\text { ampliadas para } \\
\text { não combatentes e } \\
\text { reabilitados de acidentes } \\
\text { de trabalho. }\end{array}$ & $\begin{array}{c}\text { Reformaram } \\
\text { o sistema de } \\
\text { cotas para cotas } \\
\text { contribuição. }\end{array}$ & $\begin{array}{c}\text { Deixaram } \\
\text { o sistema } \\
\text { de cotas. }\end{array}$ \\
\hline Países & $\begin{array}{c}\text { Áustria, } \\
\text { Alemanha, } \\
\text { França, } \\
\text { Itália, } \\
\text { Polônia. }\end{array}$ & $\begin{array}{c}\text { EUA, Canadá, } \\
\text { Suécia, Finlândia, } \\
\text { Dinamarca. }\end{array}$ & $\begin{array}{c}\text { União } \\
\text { Soviética }\end{array}$ & $\begin{array}{c}\text { Inglaterra, Holanda, } \\
\text { Irlanda, Bélgica, Grécia, } \\
\text { Espanha, Japão e China. }\end{array}$ & $\begin{array}{c}\text { Holanda, } \\
\text { Irlanda, Bélgica, } \\
\text { Espanha, Japão, } \\
\text { Alemanha, } \\
\text { Portugal e } \\
\text { França. }\end{array}$ & $\begin{array}{c}\text { Inglaterra } \\
\text { e Antria. }\end{array}$ \\
\hline
\end{tabular}


Tanto para verificar se a empresa está obrigada a ter pessoas com deficiência no seu quadro como para fixar o percentual de cargos a serem preenchidos, deve ser utilizado o número de empregados da totalidade de estabelecimentos da empresa no Brasil (BRASIL, 2001). Não há exigência legal para que os empregados com deficiência sejam distribuídos proporcionalmente entre os estabelecimentos, sendo essa uma decisão interna da empresa (BRASIL, 2001) Entretanto, com base no respeito às comunidades locais, recomenda-se a distribuição proporcional entre os diversos estabelecimentos. No interior do País, muitas vezes não há empresas locais com cem empregados e as filiais de empresas com sedes em outras cidades são as únicas chances de inserção no trabalho de pessoas com deficiência que lá residem.

Não é permitido que os empregados com deficiência fiquem em setor isolado na empresa, pois essa é uma atitude segregacionista que não possibilita a integração social desse segmento e elimina as suas possibilidades de progresso no emprego. Por essa razão, recomenda-se que, na medida do possível, em todos os setores da empresa sejam alocadas pessoas com deficiência (ORGANIZAÇÃO..., 1983).

Para a lei brasileira, os empregados com deficiência contratados por empresa terceirizada náo contam para fins de comprovaçáo de preenchimento da cota da tomadora (BRASIL, 2007). A legislação prevê reserva de cargos que devem ser preenchidos pela empresa. Dessa forma, os empregados da empresa terceirizada somente contam para esta.

Nas empresas, a equipe que efetua a seleçáo deve estar preparada para viabilizar a contratação desse segmento. Principalmente, precisa ter claro que as exigências a serem feitas devem estar adequadas às peculiaridades que caracterizam as pessoas com deficiência (BRASIL, 2007). Antes da obrigatoriedade de contrataçấo dessas pessoas, raras eram as empresas que as empregavam. Portanto, a elas não foram dadas oportunidades para ter em seu currículo a experiência profissional.

De uma forma geral, das pessoas com dficiência, não se deve exigir experiência (BRASIL, 2007). Quando a experiência for efetivamente necessária ao desempenho da função, a própria empresa deve oportunizar que a pessoa adquira internamente as habilidades, a postura de trabalho e os conhecimentos exigidos para o exercício de certos cargos. Quanto à escolarização, às pessoas com deficiência também não foram dadas iguais oportunidades; muitas vezes, a despeito de não terem a certificação, tiveram acesso ao conhecimento por meio do apoio da família ou da comunidade local. Por outro lado, muitas vezes é exigido, de forma generalizada, um patamar de escolaridade que não é compatível com as exigências de fato necessárias para o exercício das funçóes. Assim sendo, ao candidato deve ser dada a oportunidade de fazer um teste para revelar suas reais condiçôes de realizar o trabalho (ORGANIZAÇÃO..., 1983).

O modelo atual de organização do trabalho impôs um perfil de trabalhador polivalente, que desempenha inúmeras funçôes; dependendo das limitações impostas pela deficiência, a pessoa não consegue desenvolver o conjunto das funçóes inseridas num mesmo cargo. Entretanto, pode realizar parte delas. A empresa, sempre que possível, deve verificar a possibilidade de desmembrar as funçóes de forma a adequar o cargo aos candidatos (ORGANIZAÇÃO..., 1983).

Segundo a lei, a pessoa com deficiência tem direito à jornada especial de trabalho, pode ter horário flexível e reduzido, com proporcionalidade de salário, quando tais procedimentos forem necessários em razão do seu grau de deficiência (BRASIL, 1999).

Com relação à colocação, o Decreto 3.298/99, no seu artigo 35, define as modalidades de inserção da pessoa com deficiência, como sendo: competitivo, seletivo e por conta própria. O que chama a atenção é a modalidade seletiva, que prevê procedimentos e apoios especiais, em razão do grau de comprometimento e da incapacidade da pessoa com deficiência para executar uma atividade laboral. Este artigo também define quais seriam as condiçôes facilitadoras: horários flexíveis e adequação do ambiente de trabalho, e as entidades beneficentes de assistência social poderão intermediar a modalidade de inserção seletiva e por conta própria. A modalidade por conta própria pode ser sob a forma de trabalho autônomo, cooperativo ou em regime de economia familiar (BATISTA, 2002).

A avaliação da pessoa com deficiência deve ser especial e levar em conta as implicaçóes de suas limitações na produtividade. A própria CLT parte do pressuposto de que o rendimento desse grupo é menor, já que não autoriza sua utilização como paradigma para fins salariais. Se usados os critérios utilizados como padrốes de avaliaçáo, náo estariam sendo respeitadas as peculiaridades dessas pessoas (BRASIL, 1999).

Não há previsibilidade legal de estabilidade para o empregado com deficiência. No entanto, para garantir a reserva de cargos, para a dispensa de empregado com deficiência ou reabilitado, quando se tratar de contrato por prazo determinado, superior a noventa dias, e a dispensa imotivada, no contrato por prazo indeterminado, somente poderá ocorrer após a contratação de substituto em condiçôes 
semelhantes. Ou seja, a demissão de uma pessoa com deficiência implicará na contratação de outra, não sendo necessariamente um trabalhador com a mesma deficiência do substituído. Essa regra deve ser observada enquanto a empresa não tenha atingido o percentual mínimo legal. Fora desse requisito, valem as regras gerais que disciplinam a rescisão do contrato de trabalho (BRASIL, 1991).

\section{Reflexões sobre as políticas de contratação de pessoas com deficiência}

Muitos países continuam adotando o sistema de cotas, mas agregam a este leis antidiscriminação, sistemas e esquemas de contribuição para fundos de apoio. São oferecidas aos empregadores formas variadas de colaborar com a inclusáo de pessoas com deficiência no mercado de trabalho, além de empregar e pagar contribuições. As ações do setor privado no campo social são flexibilizadas por meio de articulaçóes ou parcerias das empresas entre si ou com entidades de pessoas com deficiência, que viabilizam mecanismos eficientes.

Muitos países vêm praticando a chamada "política compreensiva", que, por meio de atividades articuladas, como: reabilitação médica, reabilitação profissional, preparação para o trabalho, serviços de colocação, adaptação do trabalho, incentivos aos empregadores, sistema de cota-contribuição e cota terceirizada e apoio a programas de modificaçáo de arquitetura e equipamentos, complementam o sistema de cotas.

O sistema de cota-contribuição parte do princípio de que a sociedade e as empresas, como parte dessa sociedade, têm responsabilidade de criar condiçóes favoráveis para os cidadáos que, por causa congênita, doença ou acidente, têm limitaçóes para construir suas vidas com base no trabalho. No sistema de cota-contribuição, a obrigação mais alta das empresas é oferecer oportunidades de trabalho. Entretanto, quando isso é total ou parcialmente impossível, essas empresas ficam obrigadas a recolher certa importância para uma instituição específica, como compensação à parcela da cota legal não preenchida. Nesse sistema, a contribuição é feita como última alternativa, pois a prioridade é incluir as pessoas com deficiência no mercado de trabalho. Os países que adotam esse sistema procuram evitar que os empregadores "comprem" a dispensa de sua responsabilidade social ${ }^{4}$ (PASTORE, 2000).

Segundo o autor supracitado, os recursos das contribuiçôes são redirecionados para o mercado na forma de estímulos às empresas para preencher cotas não preenchidas ou para ultrapassar cotas já preenchidas. Ou seja, uma parte do dinheiro das contribuiçóes é usada para ajudar as empresas a remover barreiras e viabilizar contrataçóes, e outra parte dos recursos é investida nas entidades para pessoas com deficiência para educação e qualificação profissional. Quanto à eficiência e à eficácia da destinação dos recursos gerados pelos fundos de contribuição, os sistemas que apresentam melhores resultados são os que canalizam as contribuiçôes para nichos de mercado comprovadamente estratégicos para o emprego das pessoas com deficiência; por exemplo, empresas que, com pequena ajuda, passam a contratar mais do que contratavam e empresas articuladas com instituições de habilitação e reabilitação.

Tanto na Alemanha quanto na França, as contribuiçóes são revertidas de um lado para a adequação da empresa e, de outro, para a reabilitação e a qualificação profissional das pessoas com deficiência. A utilização do sistema de cota-contribuição diminui a responsabilidade do sistema de cotas isoladas, gera recursos para melhorar tanto a situaçáo das pessoas com deficiência quanto das empresas para recebê-las (PASTORE, 2000). A contribuição não deve ser vista como mais um encargo social.

Estudos mostram que nas sociedades em que há exclusivamente o sistema de cotas, como no Brasil, nem sempre a cota legalmente determinada pode ser preenchida (VASCONCELOS, 2006; PASTORE, 2000; MOMM, 1998). O sistema de cota-contribuição permite às empresas exercer sua responsabilidade social, por meio do pagamento da contribuição, que é revertida para a qualificação das pessoas com deficiência que estão em busca de emprego e para financiar projetos de adequaçáo das empresas, eliminando barreiras e viabilizando a contratação.

Quanto ao sistema de cotas isoladas brasileiro, o percentual fixo por empresa e não por estabelecimento impóe sobre as grandes empresas cotas elevadas e de difícil preenchimento. Provavelmente, a flexibilização do sistema de cotas por estabelecimento facilitaria a contratação e a viabilização de ações descentralizadas, que consideram as características sociais locais, tanto na preparaçáo das pessoas com deficiência a ser contratadas quanto nas empresas para a contratação (PASTORE, 2000).

Segundo Pastore (2000), é necessário expandir as modalidades de contratação de pessoas com deficiência no Brasil, incluindo-se o trabalho por projeto, no qual a pessoa é contratada para um trabalho que tem começo, meio e fim determinados, o 
trabalho por tarefa, o trabalho autônomo, cooperado, "free lancer", domiciliar, a subcontratação, a terceirização, o teletrabalho, o telecomuting e várias outras formas de trabalho intermitente, sem vínculo empregatício.

Deve-se considerar a necessidade de inclusão das pessoas com deficiência no mercado de trabalho; no entanto, deve-se prestar atenção para não haver precarização do trabalho dessas pessoas tal como está ocorrendo com a população de trabalhadores, em geral por meio da flexibilização do trabalho. Smith (1997) apresenta, em pesquisa realizada no cenário das empresas americanas, o aumento da flexibilidade organizacional, aumentando a contratação temporária, por tempo parcial, tempo determinado ou contratando outra empresa para acomodar suas flutuaçôes nos ciclos de produção. De acordo com a pesquisa, a maior parte dos funcionários contratados nessas condiçôes nos Estados Unidos são mulheres e negros. Essas modalidades de contratação trazem benefícios aos empregadores, já que reduzem o número de funcionários em suas folhas de pagamento. Quando a demanda de mercado diminui, as empresas amortizam seus custos diminuindo os salários e benefícios, e economizam por externalizar os custos administrativos implicados com contratação e controle de trabalhadores temporários.

Companhias reduzem o número de sua força de trabalho permanente e contratam funcionários temporários quando precisam, ou seja, cortam áreas de tarefas funcionais de seus negócios e contratam serviços de outras empresas para preencher a diferença. Essa foi uma solução encontrada para as flutuações de mercado e caracteriza-se como uma tentativa de as firmas americanas recuperarem a competitividade e a rentabilidade da época do pós-guerra. Entre 1990 e 1995, as empresas americanas cortaram cargos e 59\% destas aumentaram o uso de trabalho temporário. Os empregadores anteriormente contratavam trabalhadores temporários para substituir trabalhadores doentes, em férias, mas, nos recentes anos, eles têm contratado grande número de trabalhadores temporários para substituir as posiçóes anteriormente permanentes. Essa modalidade de trabalho caracteriza-se por baixos salários, ausência de benefícios, empregos que exigem baixa habilidade, pouco treinamento e oportunidades, e instabilidade e insegurança (SMITH, 1997). Além disso, segundo Smith (1997), existe um descontentamento tanto da categoria permanente quanto da temporária, pois está havendo uma tendência à bifurcação de habilidades e categorias, além de resistência e conflito, que se revelam entre as categorias de trabalhadores.
Outra forma de contrataçáo, dentro da modalidade de cota-terceirização defendida por Pastore (2000), é a terceirização feita por instituiçóes que possuem quadro de pessoas com deficiência e realizam contratos com empresas às quais essas pessoas prestam serviços de maneira intermitente ou contínua. Esse trabalho geralmente é realizado dentro das instituiçóes onde as empresas montam setores de trabalho. No entanto, deve-se considerar a importância dos direitos e garantias derivados do vínculo empregatício e também vale ressaltar que a inclusão visa à participação das pessoas com deficiência no ambiente de trabalho conjuntamente com os demais trabalhadores. Outra questão relevante a ser considerada é a contratação contábil, ou seja, as empresas apenas assinam o contrato com as entidades beneficentes e dispensam o trabalho das pessoas com deficiência.

Defendida por Pastore (2000), a cota terceirização apresenta outras formas de concretização; por exemplo, uma empresa, além de contratar diretamente uma parte do que lhe cabe, conta em sua cota, total ou parcialmente, as pessoas com deficiência que trabalham em empresas integrantes de sua cadeia produtiva. Dessa maneira, as pessoas com deficiência se inserem no mercado regular nas duas pontas: diretamente, quando contratados pela primeira empresa, e, indiretamente, quando trabalhando nas demais empresas da cadeia.

Apesar da tendência global de terceirização de serviços que estão fora do núcleo central do negócio, no Brasil, segundo a lei de cotas, todas as empresas acima de 100 funcionários devem contratar pessoas com deficiência. Não parece essencial para o mercado de trabalho e muito menos para as pessoas com deficiência que as cotas sejam contadas por cadeias produtivas ou redes empresariais, o que parece ser uma tentativa de diminuir as percentagens legais de contratação para as empresas. Nada se fala a respeito da responsabilidade social destas. Existe uma discussão extensa a respeito da precarização do trabalho a partir da terceirização; portanto, devem-se levar em consideração questôes relacionadas antes de se instituírem regras legitimando tal modalidade.

Segundo Momm (1998), os sistemas de cotas seduziram os governantes que superestimaram o poder da lei. Países como a Inglaterra, por exemplo, a partir de fracos resultados alcançados pela implantação do sistema de cotas isoladamente, abandonaram esse sistema e implantaram a lei antidiscriminação. Outros, como França e Alemanha, acoplaram às cotas as contribuiçôes compensatórias destinadas aos fundos de apoio para pessoas com deficiência, pelo mesmo motivo. 
Quando as empresas não querem ou não podem cumprir as cotas, esse sistema tem pouca eficiência. Os mais variados subterfúgios, inclusive legais, são usados para evitar a contratação. Outras empresas, mais pragmáticas, elevam os níveis de qualificação para o preenchimento das vagas, restringindo com isso o número de pessoas com deficiência que podem se candidatar àquele posto de trabalho. Assim, com essa estratégia, as empresas enviam às autoridades do trabalho os perfis ocupacionais desejados, deixando para estas a tarefa de constatar a inexistência de candidatos habilitados para aquelas funções.

Além disso, a precariedade do sistema educacional público brasileiro e a compreensão prevalente de que a formação profissional não é uma tarefa essencial do Estado, mas sim de natureza "privada", tornam-se os maiores obstáculos na busca do emprego (GUIMARÃES, 2002).

Outro problema apresentado pelo sistema de cotas no Brasil é a "compulsoriedade eterna" e, frente a isso, muitos empregadores, temendo gerar um passivo trabalhista expressivo a partir das primeiras contrataçóes de pessoas com deficiência, desenvolvem as mais sofisticadas estratégias de não contratação.

\section{Considerações finais}

Apesar de alguns avanços nas políticas assistenciais nas últimas décadas, como, por exemplo, os fomentos a açôes municipais para a capacitação de pessoas com deficiência para o ingresso no mercado de trabalho, bem como as açôes que visam à inclusão escolar, o Estado brasileiro ainda é incipiente, o que faz com que a maioria das entidades para pessoas com deficiência se envolva na organização de açóes para preencher a lacuna deixada pelo poder público, inclusive nas políticas de habilitação e inclusão no trabalho.

Ações direcionadas à infraestrutura das cidades, como a acessibilidade e os transportes adaptados, são outros exemplos que apontam a dificuldade enfrentada pelas pessoas com deficiência para participarem da vida cotidiana.

Como apresentado, outros países adotam estratégias complementares às cotas, estratégias estas realizadas por meio do poder público em parceria com o setor privado, gerando condiçóes para a qualificação profissional das pessoas com deficiência e a adequação dos locais de trabalho. Assim, cabe ao governo o papel de garantir ambiente propício para que essas atividades de preparação bilateral venham a ser desenvolvidas e sirvam de base para viabilizar o sistema de cotas, bem como as demais providencias necessárias para seu sucesso.

Essas parcerias partem do princípio de que a sociedade e as empresas, como parte dessa sociedade, têm responsabilidade de criar condições favoráveis para que os cidadáos construam suas vidas com base no trabalho.

Verifica-se que o impacto positivo dos sistemas de cotas é reduzido. A simples imposição de uma obrigatoriedade não garante que ela seja cumprida e muito menos que as empresas venham a oferecer, de bom grado, condiçôes condignas de trabalho para as pessoas com deficiência.

\section{Referências}

BATISTA, C. A. M. A inclusão da pessoa portadora de deficiência no mercado formal de trabalho: Um estudo sobre suas possibilidades nas organizaçóes de Minas Gerais. 2002. 241 f. Dissertação (Mestrado em Ciências Sociais)-Pontifica Universidade Católica de Minas Gerais, Belo Horizonte, 2002.

BRASIL. Decreto no 93481, de 29 de outubro de 1986. Dispóe Sobre a Atuação da Administração Federal No que Concerne as Pessoas Portadoras de Deficiencias, Institui a Coordenadoria para Integração da Pessoa Portadora de Deficiencia - Corde, e da Outras Providencias. Diário Oficial da República Federativa do Brasil, Brasília, DF, 30 out. 1986.

BRASIL. Constituição (1988). Constituição da República Federativa do Brasil. Diário Oficial da República Federativa do Brasil, Brasília, DF, 1988.

BRASIL. Lei no 8.213, de 24 de julho de 1991. Dispóe sobre os Planos de Benefícios da Previdência Social e dá outras providências. Diário Oficial da República Federativa do Brasil, Brasília, DF, 25 jul. 1991.

BRASIL. Decreto no 3.298, de 20 de dezembro de 1999. Política Nacional para Integração da pessoa com deficiência. Diário Oficial da República Federativa do Brasil, Brasília, DF, 21 dez. 1999.

BRASIL. Instrução Normativa no 20, de 19 de janeiro de 2001. Dispóe sobre procedimentos a serem adotados pela Fiscalização do Trabalho no exercício da atividade de fiscalização do trabalho das pessoas portadoras de deficiência. Diário Oficial da República Federativa do Brasil, Brasília, DF, 29 jan. 2001.

BRASIL. Ministério do Trabalho e Emprego. Anuário Estatístico RAIS. 2002. Disponível em: <http://anuariorais.caged.com.br/index1. asp?pag=estabelecimento>. Acesso em: 15 ago. 2006.

BRASIL. Pessoas com deficiência conquistam mais emprego. Em Questão, ed. 1277, p. 01, 2011.

BRASIL. Ministério do Trabalho e Emprego. A inclusão de pessoas com deficiência no mercado de trabalho. Brasília: MTE, SIT, DEFIT, 2007. 
BUCHALLA, C. M. (Org.). Classificaçâo Internacional de Funcionalidade, Incapacidade e Saúde - CIF. São Paulo: Editora da Universidade de São Paulo, 2003.

CLEMENTE, C. A. Caminhos da Inclusão: é só o início de uma longa estrada, mas iniciativas positivas mostram um horizonte para a pessoa com deficiência. Osasco: Espaço da Cidadania, 2005.

DUCKWORTH, S.; MCGEER, P.; KEARNS, D.; THORNTON, P. Study Report: United Kingdom. Geneva: Internacional Labour Office (OIT), 1998.

GUIMARÁES, N. A. Por uma Sociologia do Desemprego. Revista Brasileira de Ciências Sociais, v. 17, n. 50, p. 104-121, 2002. http://dx.doi.org/10.1590/ S0102-69092002000300007

GUNDERSON, M.; GILDINER, A.; KING, A. Study report: Canada. Geneva: International Labour Office (OIT), 1998.

INSTITUTO BRASILEIRO DE GEOGRAFIA E ESTATÍSTICA - IBGE. Novos dados do Censo 2000 confirmam avanços na educação e revelam mudanças nas estruturas familiar e domiciliar, 2001. Disponível em: <http://www.ibge.gov,br/home/presidencia/ noticias/08052002tabulacao.shtm $>$. Acesso em: 11 ago. 2002.

JANNUZZI, G. M. A luta pela educação do deficiente mental no Brasil. Campinas: Cortez/Autores Associados, 1985.

KARLSSON, A. Study Report: Sweden. Geneva: International Labour Office (OIT), 1998.

MOMM, W. Employment Prospects for disabled People in Transition Countries. Geneva: International Labour Office (OIT), 1998.

ORGANIZAÇÃO INTERNACIONAL DO TRABALHO - OIT. Convenção no 159 sobre Reabilitaçâo Profissional de Pessoas Portadoras de
Deficiência. Genebra: International Labour Office (OIT), 1983. Disponível em: <http/dhnet.org.Br/ direitos/sip/lex.64.htm>. Acesso em: 10 nov. 1999.

ORGANIZAÇÃO INTERNACIONAL DO TRABALHO - OIT. Convenção no 168 relativa à Promoção do Emprego e à Proteçáo contra o Desemprego. Genebra: International Labour Office (OIT), 1988. Disponível em: <http:// www.oitbrasil.org.br>. Acesso em 10 dez. 2007.

ORGANIZAÇÃO INTERNACIONAL DO TRABALHO - OIT. Decreto Legislativo no 89. Genebra: International Labour Office (OIT), 1992.

O'LEARY, P.; DEAN, D. Study Report: United States. Geneva: International Labour Office (OIT), 1998.

ORGANIZAÇÃO DAS NAÇÓES UNIDAS - ONU. Word Program of Action Concerning Disabled Persons. Centro de Documentaçáo e Informação do Portador de Deficiência - CEDIPOD, 1992. Resolução 37/52, documento $\mathrm{A} / 37 / 51$.

PASTORE, J. Oportunidades de trabalho para portadores de deficiência. São Paulo: LTr, 2000.

SIMONELLI, A. P. Contribuiçôes da análise da atividade e do modelo social para a inclusão no trabalho de pessoas com deficiência. 2009. 221 f. Tese (Doutorado em Engenharia de Produção)-Universidade Federal de Sáo Carlos, São Carlos, 2009.

SMITH, V. New forms of work organization. Annual Review of Sociology, v. 23, p. 315-339, 1997. http:// dx.doi.org/10.1146/annurev.soc.23.1.315

THORNTON, P. Employment Polices for Disable People in Eighteen Countries: A Review. New York: Social Policy Research, University of New York, 1999.

VASCONCELOS, F. D. Ironias da desigualdade: Políticas e práticas de inclusão de pessoas com deficiência física. 2006. 206 f. Tese (Doutorado em Saúde Coletiva)-Universidade Federal da Bahia, Salvador, 2006.

\section{Autores}

\section{Angela Paula Simonelli}

Doutora em Engenharia de Produção, Universidade Federal de São Carlos - UFSCar, São Carlos, SP, Brasil Joáo Alberto Camarotto

Professor Doutor do Departamento de Engenharia de Produção, Universidade Federal de São Carlos UFSCar, São Carlos, SP, Brasil

\section{Contribuição dos Autores}

Angela Paula Simonelli: concepção do manuscrito, pesquisa bibliográfica, redação do texto e sua revisão. João Alberto Camarotto: orientador do programa de Pós-Graduação em Engenharia de Produção, local em que esta pesquisa, parte de tese de doutorado, foi desenvolvida; este autor orientou a primeira autora no desenvolvimento da pesquisa, bem como o desenvolvimento do manuscrito e sua revisão. 


\section{Notas}

${ }^{1}$ Parte integrante da Tese de Doutorado de Simonelli (2009).

${ }^{2}$ A partir dessa estimativa da ONU, calculava-se em 1992 que existiam no Brasil 7,2 milhóes de deficientes mentais, 2,9 milhóes de deficientes físicos, 2,2 milhôes de deficientes auditivos e 725 mil deficientes visuais.

${ }^{3}$ A respeito da terminologia adotada, cumpre explicitar que se optou por utilizar a designação 'pessoa com deficiência' para fazer referência aos sujeitos, objetos deste estudo. A utilização do termo genérico mais corrente: pessoa portadora de necessidades especiais é um fator complicador, na medida em que não permite identificar de que sujeito se está falando, exigindo sempre a adjetivação do termo. Como assinalou Jannuzzi (1985), a variação terminológica é uma constante e mais parece destinada a minimizar a forma pejorativa com que essas pessoas são percebidas socialmente. As mudanças, contudo, não têm mais que um efeito transitório. Dessa forma, encontra-se uma grande variabilidade de designaçóes nas fontes utilizadas. No decorrer deste estudo, portanto, poderão ser encontrados os termos: excepcionalidade, anormalidade, portadores de necessidades especiais, portadores de necessidades educativas especiais, pessoas portadoras de deficiência, sempre em respeito às fontes. Mesmo reconhecendo que esses termos podem ter implicaçôes mais amplas (como a referência às altas habilidades), no âmbito deste estudo, devem ser compreendidos, sempre como referência à pessoa com deficiência.

${ }^{4} \mathrm{Na}$ Alemanha, por exemplo, os empregadores estão terminantemente proibidos de se isentar da obrigação de empregar a cota. Isso é permitido apenas em casos muito bem justificados. Na França, a contribuição é paga depois de esgotadas todas as possibilidades de emprego. 